\title{
Thinking about the nucleus
}

\author{
M. Biggiogera \\ Dipartimento di Biologia Animale, Laboratorio di Biologia Cellulare, Università di Pavia, Italy
}

(C2003, European Journal of Histochemistry

Correspondence: Marco Biggiogera, Dipartimento di Biologia Animale, Laboratorio di Biologia Cellulare, Università di Pavia, piazza Botta 10, 27100 Pavia, Italy.

E-mail: marcobig@unipv.it

European Journal of Histochemistry 2003; vol. 47 issue 1 [Jan-Mar]:91-92

0 ne of the most sacred freedom in the scientific world is the freedom to challenge: to test new ideas against old, established ones, to try and explain facts and results by means of new interpretations, sometimes even to believe the unbelievable. Obviously, a consequence of this freedom to challenge is the freedom to be challenged, i.e. any new, earth-shaking theory can be challenged by other scientists. During the summer of 2001, a paper published by Iborra et al. (2001) pushed the scientific community to rethink about one of the basic mechanisms of cell biology: translation. According to this paper, mRNA could be translated, although in a limited amount, also in the nucleus. Other papers confirming these data were soon published and these findings were more or less quietly accepted. However, in January 2003, two papers (Dahlberg et al., 2003; Nathanson et al., 2003) repeated carefully the experiments of Iborra and coworkers and concluded that there was no proof of nuclear translation. In this way, we are restored to our previous dogma of nuclear transcription and cytoplasmic translation.

As a consequence of this discussion, the biology of the cell nucleus has again become one of the most debated issues. Researches on the nuclear structure and function thus enjoy a sort of renaissance and one of the main topics is represented by the nucleolus. This organelle, long regarded only as the place of ribosome biogenesis, has entered a new life with the discovery of its involvement in biological processes other than rRNA synthesis (Olson et al., 2002; Politz et al., 2002). In a recent paper, Smetana (2002) has summarized the data on the nucleolus of normal and pathological blood cells and, given its participation to cell resting, proliferation and differentiation, underlined its role of marker for evaluating the cell state also in pathological conditions.

Nucleoli are indeed dynamic organelles, which may undergo activation/inactivation cycles; this is especially apparent in specific cell systems such as root primordia in plants. Acevedo et al. (2002) have described the behaviour of ribosomal genes toward activation in sugarcane simply by water imbibition of roots.

Nucleolar components are growing in number every year (Andersen et al., 2002) and for many of them a specific function is still lacking. This is the case of phosphorylated c-myc which has been shown to colocalize with fibrillarin in HeLa cells (Soldani et al., 2002).

Ortiz et al. (2002) have studied the distribution of RNA and DNA within the synaptonemal complex in spermatocytes. Their findings that RNA is associated with DNA-containing thin filaments and with the axial chromatin elements of the synaptonemal complex suggest the possibility that nuclear RNA could be involved in homologous chromosomes pairing: this would add another possible function to RNA other than the already established code containing, catalytic, regulatory and RNA interference activities (McManus and Sharp, 2002).

In fact, the cell nucleus as a whole must be considered as a dynamic organelle not only in cell proliferation and differentiation, but even during apoptotic cell death. It is well known that apoptosis may be induced by a wide variety of external stimuli, from anticancer drugs to microgravity (see, for recent reports published on EJH, Uva et al., 2002; Bonanno et al., 2002), and that it generally takes 
place through a largely stereotypical series of cellular modifications. The evidence exists that the early onset of apoptotic signs which occur at the cell surface may be paralleld by concomitant morphological and molecular events at the nuclear level (see also Soldani et al., 2002), which could be likely taken as potential apoptotic hallmarks.

It may be easily foreseen that basic research on the structure and function of the cell nucleus and the nucleolus will be increasingly important for understanding the mechanisms underlying major biological processes such as cell differentiation and pathology, the control of normal and tumor cell growth, or the role of cell death in development and tissue homeostasis.

\section{References}

Acevedo R, Cuadrado A, De la Torre C, Moreno Diaz de la Espina S. Behaviour of ribosomal genes and nucleolar domains during activation in sugarcane (Saccharum officinarum L.) root primordia: from the unsoaked quiescent state to the steady state of proliferation. Eur J Histochem 2002; 46:143-58.

Andersen JS, Lyon CE, Fox A., Leung A., Lam YW, Steen H., Mann M, Lamond AI. Directed proteomic analysis of the human nucleolus. Current Biology 2002; 12:1-11.

Bonanno E, Tagliafierro G, Carlà EC, Montinari MR, Pagliara $P$, Mascetti G, Spagnoli LG, Dini L. Synchronized onset of nuclear and cell surface modifications in 4937 cells during apoptosis Eur J Histochem 2002; 46: 61-74.

Dahlberg JE, Lund E, Goodwin EB. Nuclear translation: What is the evidence? RNA 2003; 9:1-8.

Iborra FJ, Jackson DA, Cook PR. Coupled transcription and translation within nuclei of mammalian cells. Science 2001;293, 1139-42.

McManus MT, Sharp PA. Gene silencing in mammals by small interfering RNAs. Nat Rev Genet 2002; 3:737-47.

Nathanson L, Xia T, Deutscher MP. Nuclear protein synthesis: A reevaluation. RNA 2003; 9:9-13.

Olson MOJ, Hingorani K, Szebeni A. Conventional and nonconventional roles of the nucleolus. Int Rev Cytol 2002; 219: 199-266.

Ortiz R, Echeverría OM, Ubaldo E, Carlos A, Scassellati C, Vázquez$\mathrm{Nin}$ GH. Cytochemical study of the distribution of RNA and DNA in the synaptonemal complex of Guinea-pig and rat spermatocytes. Eur J Histochem 2002; 46:133-42.

Politz JC, Lewandowski LB, Pederson T. Signal recognition particle RNA localization within the nucleolus differs from the classical sites of ribosome synthesis. J Cell Biol 2002; 159:411-8.

Smetana K. Structural features of nucleoli in blood, leukemic, lymphoma and myeloma cells. Eur J Histochem 2002; 46:125-32.

Soldani C, Bottone M.G, Biggiogera M, Alpini C, Scovassi A.I, Martin T, Pellicciari C. Nuclear localization of phosphorylated c-Myc protein in human tumor cells. Eur J Histochem 2002; 46: 377-80.

Uva B.M, Masini M.A, Sturla M, Bruzzone F, Giuliani M, Tagliafierro G, Strollo F. Microgravity-induced apoptosis in cultured glial cells. Eur J Histochem 2002; 46: 209-14. 